\title{
Role of Empathetic Engineering in Building More Resilient Green Economy. Case Study on Creating Resilient Self Sufficient Food Security Programs in Middle East
}

\author{
Mohamed Buheji \\ Founder - International Institute of Inspiration Economy- Bahrain
}

\begin{abstract}
This paper targets to investigate the influence of empathetic engineering on creating more resilience economy driven government organisation structure that delivers the socio-economic needs of the stakeholders effectively. The application of empathetic engineering is carried out by the researcher for establishing a self-sufficiency program that meant to ensure food security for a middle eastern country over a period of three years. The program covered all the farms and gardens in the specified country. The empathetic assessment helped to optimise the designing process and the integration of different jobs through understanding the best alternatives in structuring the organisation. The country benefited from establishing an integrated system and a greener economy intention that would influence the GDP and develop the country's business model in relevance to food security. The outcome of the empathetic engineering is discussed in relevance on how it created more society development, causing better resilient cost centre business models that are independent of government support yet competitive and productive.
\end{abstract}

Keywords: Empathetic Engineering, Resilience Economy, Self-Sufficiency, Food Security, Agriculture Planning, Empathy Economics, National Strategies, Green Economy, Problem Solving, Behavioural Economics, Middle Eastern Countries.

\section{INTRODUCTION}

There is a growing demand for cognitive abilities for 'change agents' to recognize and understand the thoughts, perspectives, feelings, and actions of their surrounding project community and the country needs they working for. (Eisenberg \& Strayer, 1990).

Through emotional empathy emotions of others can be experienced. Optimal time to learn and practice prosocial behaviour skills such as conflict resolution and empathy responses. Recent results from brain research have indicated that parts of the brain responsible for prosocial behaviour responses in the frontal lopes.

\section{Definition of Empathy}

Early definitions of Dymond (1949) seen that empathy can be seen from cognitive perspective thus considered empathy as the cognitive ability to recognize and understand the thoughts, perspectives, feelings and actions of other individuals, organisation, community or even country. The work of Stotland (1969) sees empathy as emotional experience absorb the emotions of the other people or the environment around. Therefore, taking into account the work of Miller and Eisenberg (1988) empathy can be summarised as an influential affective feeling that raise the ability to discriminate and identify the emotional states of the others and building the capacity to take the perspective or role of the others. This raise our capacity for evocation of a shared affective response. Thus empathy ensures that the perceived emotion of "feeling with" the others are perceived. 


\section{Empathy in Economics}

Empathy is a subject that has interested many disciplines, such as management, medicine, law, innovation and besides it has its long roots in philosophy and psychology. As empathy is now being studied for its influence by neuroscientists and its research spreading through neuroeconomics, it is rapidly growing as an area of economic decision-making.

Kirman and Teschl (2009) seen that both sympathy and empathy are concepts that have been used in economics at least since the eighteenth century giving reference to Hume (1740). Fontaine (1997) was one of the earliest whom established a link between contemporary economics and the practices of sympathy and empathy. Fontaine seen that sympathy works when our concerns is focused about the welfare of others, including concerns about the community. Whereas empathy works when total our capacity is diverted to put ourselves in someone place, thus to share even the thoughts of that person. However, one could experience that there is still a literature gap in relevance to empathy engineering and its role in enhancing the economic and socio-economic productivity. Fontaine (2001).

It is easy to trace the historical interest in empathy since Smith's Theory of moral sentiments which focused on how one should place his/her self in others situation by imagination. Smith see this is important for the economy since it give us more resilient understanding of what it would be in particular circumstances. However, empathy disappeared from the economics literature as the world lost its resilience specially after the two world wars.

With the development of game theory, researchers started to see the essential importance of individuals interacting directly and consciously with each other, as a 'common knowledge' assumption (Binmore, 1990). Which means that the individuals involved reflect on the actions of the others with whom they interact and know that the others do the same, i.e. affectively understanding the emotions the other. Singer and Fehr (2005) called this process 'mentalizing'.

\section{Empathetic Engineering}

Binmore (1994) suggested building an empathetic based models of the society and its functioning on the basis of the strategic interaction between individuals and their community. Therefore, empathy must not be considered as an essential practice that need to be embedded in all human related activities since it enables us to understand the nature of communication and the strategic interactions needed between all the community members and the environment around them.

Empathy, if conditioned or engineered it would help us to better accurately anticipate others actions and contribution. Empathetic Engineering would allow the targeted individuals, organisations and communities to be resilient and strive to understand the position of the others. Therefore, empathetic engineering highly needed here in order to live and mentalize the needs and feelings of others.

Empathetic engineering, help strategic planners and human capital and organisational structure designers to create focus on what behaviour to expect from one another in order to reach a good outcome, Koppen and Meinel (2015). While the work of Binmore (1994) empathetic engineering focus on designing how to trigger the realisation of the others while selecting the preferences belonging to each person.

\section{Empathetic Engineering and the Development of Behavioural Economics}

The interest in empathetic engineering is expected to pick-up more with the continuous developments in behavioural and experimental economics, which have now started to include 
empathy among a number of other emotions attributed to prosocial behaviour, Bowls and Gintis (2003). Since empathy is taken to be a form of visceral reaction, referring to the process of changing perspective and looking at the world from another person's point of view, researchers believe that it can be also taken to be an experience of communal feelings that promotes concern for the other person's welfare.

As with the development of Behavioural Economics, Neuro-economists have now started to look at empathy applications and the possibility of its engineering in more serious way, Singer and Fehr (2005) and Singer et al. (2006). Roughly speaking, neuro-economics tries to analyse the nature of the activation of the human brain while individuals are carrying out economic decisions or specific tasks, through different forms of typical economic experiment Fehr and Camerer (2007). Neuro-economists believe that such studies of empathetic applications will help to understand the process of how people put themselves in the place of other people.

Thus neuroscience is going to raise our ability to engineer empathetic practices and motivational reasoning. Through neuroscience, empathetic engineering would help better absorb the other person's beliefs, intentions and motivations, but to a feeling of shared experience with the other person's sensations and emotions.

The recent development of Social Neuroscience is expected to help empathetic engineering to develop further since it differentiates between the main two empathic processes cognitive empathy and affective empathy. A cognitive empathy refers to the capacity to represent other people's intentions and beliefs, while an affective empathy refers to the capacity to share the feelings of others. This second type of empathy is very important for both resilience and inspiration economy since the affective sharing of a particular emotion or sensation, and experiencing the same feelings may lead to a better understanding of that person's perspectives and also influencing them indirectly.

\section{Empathetic Engineering in Communities Problem Solving}

Through empathetic engineering 'empathetic identification' can be built. This identification is crucial for human communities' problem solving, because without it equilibrium between preferences and organisational, or community's needs won't sustain. Through empathetic engineering the interest of community is focused and so the feelings of its needs. Thus help us to meet the national interest, or the community interest and not only someone's personal feelings only.

The unique application of empathetic engineering in problem solving can help us see the big picture when tackling any sensitive issue that is needed for the benefit of a nation or a community. Empathetic Engineering can be applied there for solving problems in relevance to healthcare, education, engineering, etc. In this paper building a country's self-sufficiency and enhancing its food security is investigated through actual longitudinal implementation.

\section{Self-Sufficiency and Food Safety in Middle Eastern Countries}

Clapp (2017) mentioned about the growing importance of food self-sufficiency in creating a food security for many countries since the early of this 21st century. With the wake up of the international food crisis in 2007, many countries reviewed and assessed their farming and gardening practices and tried to establish a safety net from the volatility of imported food and the same time enhance the transformation towards greener economy. This wake up was especially important for Middle East Countries and specially in countries where they are totally dependent on oil as a source of importing food from all over the world. In these countries self- 
sufficiency was not part of the national plan, or even properly well stated in most of their vision.

Middle Eastern countries have been also always critiqued by economists for failure in their approach for solving food security where socio-political control the priorities of socioeconomic efficiency and economic. This paper presents another way of overcoming this problem by utilising empathetic engineering in re-designing a country's farm and garden. Empathetic engineering is used here to ensure the country's security in food and its selfsufficiency.

\section{Relation between Self-Sufficiency, Empathetic Engineering and Resilience Economy}

Most dictionaries define resilience in terms of the ability to recover quickly from the effect of an adverse incident. Therefore, in Buheji (2018) resilience economy (RE) was defined as the recovery enablers, tools and capacity of the economy or the socio-economy to leap back. When the systems are built based on empathetic thinking utilising empathetic engineering and with a target to be sustainable by being self-sufficient it probability of leap back efficiently is much higher.

Having a self-sufficient system means a system with ability to produce competitive products and services, in this paper in relevance to supply of food with high guaranteed safety design to recover quickly from shocks and to withstand the effect of a shock, or even to it altogether.

Both empathetic engineering and self-sufficiency being to resilience economy the type of community that would have the mindset to be ready to unique coping mechanisms.

\section{METHODOLOGY}

Using both a country's essential need for more transformation for food self-sufficiency and empathetic engineering, the researcher undertaken these needs as framework for his project. Here for the purpose of contractual agreement the name of the country shall be Country (A). The identity of the country and the entities in the case study is not disclosed due to the sensitivity of such project to country's security and vision of its quality of life.

The project has taken 32 months where stages of assessment, gap analysis, evaluation, early structuring, setting national strategies, setting main team and then setting detailed organisational structuring along with communication plan.

The researcher applied the empathetic engineering in designing any structures that support the effective transformation towards more self-sufficiency without increase the demands on the limited resources. Since food economic decision making is also very important for areas of agriculture planning, this was taken into consideration as part of enhancing country's (A) needs for more resilience economy. Resilience would be embedded as part of the researcher empathetic mindset during the process of assessment, analysis and strategic design development, in reference to Zhang's et. al (2015).

In the Arab world specifically and in developing countries in general, the creation and maintenance of such self-sufficient government and towards more of green economy have been very bureaucratic and classical, mainly due to the hierarchical mindset that handled such specialised fields. Therefore, through empathetic engineering mindset, the focus would be on creating a totally resilient yet competitive agricultural industry that would ensure the supply of the country (A) secured food. 
Due to the high nature of the country's total dependence on external agricultural food supply, a model was agreed to be built so that it would be both resilient and self-sufficient. Following field observations that were collected from visits to different gardens and green field in the country, it was clear that the methodologies for the types and nature of agriculture and nurseries distributed in all country regions of country (A) need to be done in empathetic way. When this project started there was no evidence of any integrated and resilience in relevance to the agriculture and its contribution to the socio-economy, despite the nature and size of the farming area.

\section{CASE STUDY}

\section{Agriculture and Farming for more Resilient Economy}

In today's workplace the nature of how people "work together" is evolving. In resilient driven economy teamwork would transform more to be based on collaboration where the empathetic relation of people sharing the same space is expected to push them to effectively coordinate their efforts in the pursuit of stronger common goals. Today this apply even to farmers and agricultural workers who are geographically dispersed and even may never see each other, yet they are organizationally linked through telecommunications and information technologies as they attempt to achieve interdependent organizational tasks (Townsend, et. al, 1998).

Such type of thinking was abstracted by the researcher with specific application to agriculture and farming business. The speed of the advances in technology, the mounting time pressure, and the demands of increasingly global and dynamic markets were all taken into consideration and blended with the empathetic engineering mindset.

\section{Consideration and Empathy of Agriculture Industry in Arab World}

Consideration of empathetic engineering in structuring agriculture industry in country $(A)$ would help to establish not only better communication relationship, but even better behaviours towards productivity and effective planning for food security.

In agriculture structuring, farming and gardening outcomes would be more effective if built around more resilient behaviours and characteristics that would lead to an established productive and competitive culture. This resilience in behaviours start with having agricultural and farming teams that can assert authority without being perceived as overbearing or inflexible, while being extremely effective at building resilient communication with peers while delivering best outcome. The ability to clarify role of the different relationships taken by the researcher was taken in reference to the way of building passion and empathy as per the work of Jarvenpaa \& Leidner (1998) and Kayworth \& Levine (1998). Since country (A) target to transform more towards green economy, unique empowerment, training and mentorship structure need to be considered. Here empathetic engineering was used again to build higher understanding (empathy) on what would exhibit greater positive influence on the farming and gardening of team performance.

\section{Purpose of Country (A) Project}

The purpose of having structuring of all the farms and gardens that belongs to government in Country (A) was to create a holistic system of food production that would ensure effective minimum level and diversity of green food and related poultry and dairy productions, i.e. vegetables, fruits, meats and dairy products. Thus in a way to ensure more secure cycle of food production with more resilient management of the different resources including the human capital and the knowledge assets captured over the years. 
The project included the provision and management of animal care, beautification of gardens and palaces, requirements for gardens and farms services delivery and all the logistics services relevant to gardening and farming protection and distribution. Grading and packaging of food and green products were also part of the services expected from these green units.

\section{Project Assessment and Planning Stage}

The project gone through first a detail assessment of what is available in Country (A) in relevance to gardening and farming verses what is really needed at this early stage towards being more self-sufficient. Based on this gap analysis, new planning based on empathetic engineering taken into consideration the needs of the stakeholders and the employees in each type of job in the system.

It is worth to mention that project carried also the responsibility for evaluating the existence of veterinary and livestock management within the Farming and Gardening responsibilities. It was as if the researcher if establishing a holistic eco system. There were three gardens that have small family Zoo's and also breading of livestock animal as Caws, Sheep, Birds, Donkeys, Tigers, Lions, etc.

The assessment using Empathetic Engineering Mindset focused directly on the strength of the Livestock Protection Unit and the specialty of a team that taken care for the rare wild animals and birth control. The team were found to be very competent to meet the highest international standards for adequate sources of nutrition and hygiene with prevention from infection and transmission of diseases to humans and animals.

\section{Analysis of Country (A) Self-Sufficiency Requirements}

Analysing the requirements for service delivery of gardens and farms, using empathetic engineering again lead to suggesting the promotion of bioenergy sources (organic farming unit) as it was under demand for both the customers and to improve the quality of productions grading.

Empathetic engineering lead to pin point the importance of farms and garden unit that focus on Productive Capacities Management. This meant that each farm or garden in country (A) need to be seen as an integrated cost or profit centre, where it would be given semiindependence in the management of farmers, technicians, warehouses, seasonal planning and in dealing with crises, nursery production and collaborations with nearby farms nurseries.

The analysis shown that country (A) is highly competent to decentralise each cost centre since each carried its own tools, equipment, prevention assets, veterinary services. However, the analysis showed also country (A) really need to unify through it national strategic planning the farms and gardening goals to reach the main target of Self Sufficiency and food security. Therefore, the analysis emphasis that agricultural planning, economic production and marketing for farms and gardening need to be formulated through strategic team is monitored and evaluated for their performance every three years.

The empathetic engineering focused on the importance of transferring and sharing knowledge from the agriculture and greenery consultants to the field engineers, farmers and gardeners. A team in the field of economics and agricultural evaluation were proposed to be formulated to ensure that knowledge accumulated by the research is transferred effectively. 


\section{Empathetic Design of Country (A) Self-Sufficiency Structure}

Through a survey that was built on empathetic engineering and which included all the farms and the gardens in country (A); the early needs for a self-sufficiency structure was identified. The survey results showed that establishing a green economic management unit (EMU) with a high authority would improve the outcome of the green production in country (A) compared to cost enquired and would enhance green economy management, besides giving more accurate evidence of the contribution of the gardens and farms to the GDP of the economy.

The survey showed that it is important for the new EMU team to undertake intensive courses in agricultural and animal feasibility studies. A technical coordinator is required for the directorate to coordinate between the departments on issues related to economic feasibility and costing. The empathetic engineering analysis proposed further that the EMU should be supported with a legal researcher that would manage the contracts between the third parties and the directorate.

A national self-sufficiency program (NSSP) was proposed for government legislatures. The program was designed based on the empathetic engineering assessment and planning exercise carried the researcher. The proposed program was suggested to be linked to the country's vision 2030. The purpose of the legislation is to support the efforts for freeing the business model of going towards contribution of green economy in the country's GDP with minimal bureaucracy which the EMU team would maintain in the long run. NSSP was empathetically designed to transform the country to another less depleting resources dependent economy and reduce its dependence on external main food imports. NSSP set a comprehensive performance management of green production plans for 3-5-10 years. NSSP linked also the current economic vision 2030 to the green production output and outcome expected.

The NSSP detailed plans included the palaces most suitable as per the type of corps and the markets that it can be sold in for getting the best return and in the same time reducing or controlling the cost of the similar imported corps or food.

Through the empathetic engineering programs development of agriculture and green system found to be beyond the normal known lands, water, human capital and production economy. The researcher found that a total revamp of the irrigation system and engineering need to be develop in a way that it would help to enhance on the return of the capital employed (ROCE), as for example in the non-calculated cost of the irrigation from the wells, besides the other administrative and technical labour costs.

\section{Establishment of Self-Sufficiency Teams}

A strategic team facilitated by the researcher worked on having the empathetic thinking of the both proposed EMU and NSSP as part of future references for the pragmatic model designed for the farms and garden. Temporarily a centre of planning unit is established to ensure that plans are executed with best quality, at the best cost and with high availability. Besides, the centre was give the responsibility of follow-up.

The strategic team created assignments as per specialty for the different team members as per their professional interests and backgrounds, however encouraging the multi-discipline integration. An agricultural economic planning team, was assigned to monitor the plans for the environmental planning. Due to empathetic engineering proper planning for new farms was given to the strategic team whom responsibility goes till product planning, planning for biological control along with prevention and planning for organic agriculture. NSSP included also planning for animal management and the generation of rare wild animals. 


\section{Establishing Empathetic Engineering in the System of Country (A)}

In order to establish the empathetic engineering practices in the system of country (A), Centre for Green Economy Research and Development (CGERD) was established. CGERD targets to establish empathetic engineering in all results and outcomes targeted by the strategic team and different cost centres throughout the country. CGERD was set to utilise principles of collaboration and sharing economy to ensure effective economic projects are supported by scientific and academic teams. The CGERD is expected to take over the farms and gardens master plans updates.

Part of the efforts for establishing the empathetic engineering that takes into consideration the goal of self-sufficiency; was setting a Centre for Information Management and Quality Standards Development (CIM-QSD). CIM-QSD was established to ensure effective plants and food production and its protection information are accurate. The CIM-QSD was asked to be in charge of the procurement cost information, information technology services, livestock information, cost accounting, resource management and integration. The CIM-QSD also was given the responsibility for supervising the Technical Training Centre for Agriculture and Veterinary Medicine (TTC-AVM). This centre was given the responsibility for the assessment of the newly enrolled staff and those that goes through promotion evaluation assessment. The TTC-AVM is expected to produce a comprehensive intensive courses for new members in the different fields of specialization. A communication driven multi-disciplined program has been designed to ensure effective smooth integration of efforts and resources between all the type of farms and gardens.

The TTC-AVM was empathetically designed to support in collecting statistical evidence based references to ensure the alignment towards the targeted outcomes. The statistics are meant to address the comparisons needs between the farms and quality of production, the best practices and the lessons learned.

\section{Re-Designing the Role of the Agricultural Engineers based on Empathy and Self- Sufficiency}

Due to empathetic engineering assessment the role of agricultural engineer (AE) was promoted towards planning the season and not only supervising it. Also, the AE was give the responsibility to balance between vegetative growth and fruit growth which in turn would enhance the country's self-sufficiency program. The AE was expected also to report about the results of the periodic examination, especially in relevance to the grading level of fruits and vegetables. This means the $\mathrm{AE}$ would be more accountable for the efforts taken for preparing resources in periods of land reclamation and management as an integrated project.

To ensure effective multi-disciplined self-sufficiency driven culture, it was decided that the AE would be trained by both the TTC-AVM and the CIM-QSD and later by CGERD; to calculate the annual rate and the agricultural hours and the relate resources required for the next season. The AE is also expected to align the farms or garden plans with irrigation networks planed by the irrigation engineers. The AE's were given the responsibility for prepare quarterly an efficient list of the type essential supply needed as the seeds, fertilizers, and prevention medicines; besides an annual list for the agricultural equipment requiring the replacement, repair or maintenance.

\section{Setting the Self-Sufficient Empathetic Enabler in Country (A) Business Model}

In order to speed up the independence of the business model for each cost centre, be it a farm or a garden, all agriculture and irrigation engineers who have over five years were considered to part of the trainers' team. This model helps to increase the quality and type of practical 
training while also keeping training to be an empowerment tool and part of the annual assessment. A minimum number of training hours was enforced to be received annually for each employee.

The strategic team set a transformation team that targeted accelerating the gradual replacement of specific foreign imported green food contracts as per the defined 3-5-10 years plan. This was aligned with a program that focused on exploiting the green plants nurseries capacity.

To define criteria for structuring the business model for any farm, the CIM-QSD agreed that farms which exceeds 15 acres and have more than 5 major varieties of production would have a separate cost centre. Part of the re-design of the business model is the unification of the names of each (agricultural worker) and (farmer). Both this job integration, besides the responsibility for the workers' occupational health and safety was assigned to CIM-QSD.

The farms business model included the management of by-products as the dairy which comes from farms. Hence, fresh milk and ice cream and related dairy products were assigned to CIMQSD. This unit was responsible also for farms and garden global benchmarking, where the product and the quality of the production would be compared to similar products from different countries and even local private farms.

\section{CONCLUSION}

This paper carried a case that utilised different techniques in order to create a self-sufficient, food secured country. Even though this paper presents and explore the beginning of the story, it reviews and explores the possibilities that empathetic engineering brings to a complex issue as food self-sufficiency program for a whole nation. Despite the paper carries the limitation of time and space of reporting the whole case study, the case illustrates the importance of having empathetic engineering in the assessment, analysis and design in major project that affects countries, communities and organisations.

This fundamental paper challenges different norms and assumption such as the difficulty of creating self-sufficiency in bureaucratic governments, or creating radical change in food security mindset in Middle Eastern countries. Besides, this paper shows how empathetic engineering might profoundly contribute to creating dynamic constructive business models that brings differentiate outcome to the community, yet build also resilience economy.

\section{References}

Binmore K., Shaked A. (2010) Experimental economics: where next? Journal of Economic Behavior \& Organization 73, pp. 87-100.

Buheji, M (2018) Understanding the Power of Resilience Economy. An Inter-Disciplinary Perspective to Change the World Attitude to Socio-economic Crisis. AuthorHouse, UK.

Clapp, J (2017) Food Self-Sufficiency: Making sense of it, and when it makes sense, Food Policy, Volume 66, January, Pages 88-96.

De Waal F. B. M. (2008) Putting the altruism back in to altruism: the evolution of empathy. Annu. Rev. Psychol. 59, pp. 279-300.

Decety J., Lamm C. (2006) Human empathy through the lens of social neuroscience. Sci. World J. 6, pp. 1146-1163.

Dymond, R. F. (1950). Personality and empathy. Journal of Consulting Psychology, 14(5), 343-350.

Eisenberg, N and Strayer, J (1990) Empathy and its Development, Cambridge Studies in Social and Emotional Development. Cambridge University Press. 
Fehr E., Camerer C. (2007) Social neuroeconomics: the neural circuitry of social preferences. Trends Cogn. Sci. 11, pp. 419-427.

Fontaine P. (1997) Identification and economic behaviour: sympathy and empathy in historical perspective. Econ. Philos. 13, pp. 261-280.

Fontaine P. (2001) The changing place of empathy in welfare economics. Hist. Polit. Econ. 33, pp. 387-409.

Gul F., Pesendorfer W. (2008) The case for mindless economics. In The foundations of positive and normative economics (eds Caplin A., Schotter A., editors.), pp. 3-42 Oxford, UK: Oxford University Press.

Hume D. (1740) A treatise of human nature (eds Norton D. F., Norton M. J., editors). Oxford, UK: Oxford University Press.

Kirman, A and Teschl, M (2009) Selfish or selfless? The role of empathy in economics, Philos Trans R Soc Lond B Biol Sci. 2010 Jan 27; 365(1538): pp. 303-317.

Koppen, E and Meinel, C (2015) Knowing People: The Empathetic Designer. Journal of Design Philosophy Papers, Vol 10, Issue 1, pp 35-51.

Liu, W and Gal, D (2011) Bringing Us Together or Driving Us Apart: The Effect of Soliciting Consumer Input on Consumers' Propensity to Transact with an Organization, Journal of Consumer Research, Vol. 38, August, pp. 242259.

Oullier O., Basso F. (2010) Embodied economics: how bodily information shapes the social coordination dynamics of decision-making. Phil. Trans. R. Soc. B 365, pp. 291-301

Miller P and Eisenberg N (1988) The relation of empathy to aggressive and externalizing/antisocial behavior. Psychol Bull. 1988 May;103(3):324-44.

Ravikumar RK, Thakur D, Choudhary H, Kumar V, Kinhekar AS, Garg T, Ponnusamy K, Bhojne GR, Shetty VM, Kumar V. (2017) Social engineering of societal knowledge in livestock science: Can we be more empathetic? Vet World. Jan;10(1), pp. 86-91.

Stotland, E. (1969). The Psychology of Hope. San Francisco: Jossey-Bass.

Zhang, L; Liu, Y and Hong, J (2015) A Proposal to Support the Valuable Design Method by Redefining Empathetic Design, 3rd International Conference on Machinery, Materials and Information Technology Applications (ICMMITA 2015). file:///C:/Users/DELL/Downloads/QLTT306.pdf, Accessed: 10/1/2017 